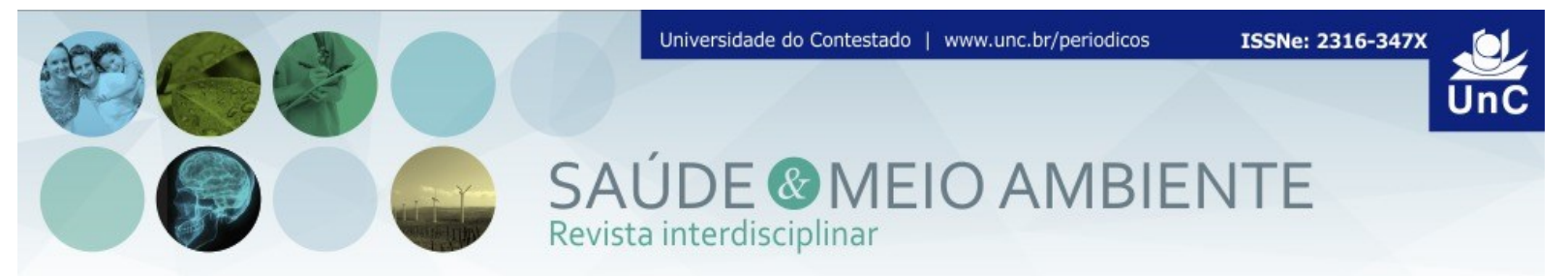

\title{
PRINCIPAIS CAUSAS DO DESMAME PRECOCE EM UMA ESTRATÉGIA DE SAÚDE DA FAMÍLIA
}

\author{
Ana Paula Agostinho Alencar ${ }^{1}$ \\ Geângela Lima do Nascimento ${ }^{2}$ \\ Petrúcya Frazão Lira ${ }^{3}$ \\ Fernando Luiz Affonso Fonseca ${ }^{4}$ \\ Ricardo Luiz Affonso Fonseca ${ }^{5}$ \\ Beatriz da Costa Aguiar Alves ${ }^{6}$ \\ Samyra Paula Lustoza Xavier $^{7}$ \\ Patrícia Agostinho da Silva Laurentino ${ }^{8}$
}

\begin{abstract}
RESUMO
Objetivo: $O$ presente estudo objetivou identificar as principais causas do desmame precoce em menores de um ano em uma estratégia de saúde da família. Trata-se de uma pesquisa de natureza exploratória com caráter descritivo e abordagem qualitativa, realizada entre os meses de março a abril de 2016 em Juazeiro do NorteCE. A amostra foi composta por 17 nutrizes com seus lactantes menores de um ano atendidos em uma Estratégia de Saúde da Família. Métodos: Foi utilizado como instrumento para coleta de dados uma entrevista estruturada. A análise dos resultados foi discutida em duas categorias, sendo uma expondo o conhecimento das mães sobre a amamentação e outra sobre os fatores que as contribuíram com prática do desmame. Resultados: Verificou-se que algumas mães possuem compreensão acerca da importância do aleitamento materno, relataram receber informações sobre a amamentação durante as consultas de pré-natal e apoio da família. Entretanto, ficou evidenciado que seu conhecimento não foi o suficiente para que elas mantivessem a amamentação. Conclusões: É importante que os profissionais da saúde em geral estejam mais motivados e agregados na construção de meios estratégicos que possam despertar nessas mulheres o interesse em realizar essa prática, trabalhando
\end{abstract}

\footnotetext{
${ }^{1}$ Mestre. Laboratório de Análises Clínicas da Faculdade de Medicina do ABC, Santo André, SP, Brasil. E-mail: anapaula@gmail.com

${ }^{2}$ Departamento de Enfermagem da Universidade Regional do Cariri (URCA), Crato. Ceará. Brasil. Email: glnascimento@hotmail.com

${ }^{3}$ Mestrado em Ciências da Educação pelo Instituto Superior de Educação Professora Lucia Dantas, Brasil. Instituto de Ciências Químicas, Ambientais e Farmacêuticas, Universidade Federal de São Paulo, Diadema, São Paulo. Brasil. E-mail: petrucya.lira@uol.com.br

${ }^{4} \mathrm{PhD}$. Serviço de Pediatria do Hospital Sírio Libanês, São Paulo. Brasil. E-mail: profferfonseca@gmail.com

5Serviço de Pediatria do Hospital Sírio Libanês, São Paulo. Brasil. E-mail: ricardoluiz@gmail.com ${ }^{6} \mathrm{PhD}$. Faculdade de Medicina do ABC. São Paulo. Brasil. E-mail: bcaalves@uol.com.br

${ }^{7}$ Especialização em Enfermagem em Emergência e Cuidados Intensivos pelo Centro Universitário São Camilo. Laboratório de Análises Clínicas da Faculdade de Medicina do ABC, Santo André. São Paulo. Brasil. E-mail: samyraplx@yahoo.com

${ }^{8}$ Departamento de Enfermagem da Universidade Regional do Cariri (URCA), Crato, Ceará. Brasil. Email: patricia laurentino@uol.com.br
} 
a partir de parcerias com outras unidades de saúde e também com poder público na busca de reverter o quadro do desmame.

Palavras-chaves: Lactante. Aleitamento materno. Desmame precoce.

\title{
MAIN CAUSES OF EARLY WEANING IN CHILDREN IN A FAMILY HEALTH STRATEGY
}

\begin{abstract}
The present study aimed to identify the main causes of early weaning in children under one year of age in a family health strategy. This is a survey of exploratory nature with descriptive and qualitative approach, held between March and April of 2016 in Juazeiro do Norte-CE. The sample was composed of 17 nursing mothers with their infants under one year of age treated in a Family Health Strategy. It was used as an instrument for data collection a structured interview. The data were organized in accordance with the technique of content analysis. The analysis of results was discussed in two categories: one exposing the knowledge of mothers about breastfeeding, and another on the factors that contributed with practice of weaning. It was found through research that some mothers have an understanding about the importance of breastfeeding, reported receiving information about breastfeeding during the prenatal consultations and support from family, but their knowledge was not enough to make them keep breastfeeding, therefore it is important that health professionals in general are more motivated and aggregate in the construction of strategic resources that can service these women the interest in conducting this practice, working from partnerships with other health units and also with public power in pursuit of reversing the instrument of weaning.
\end{abstract}

Keywords: Infant. Breastfeeding. Early weaning.

\section{INTRODUÇÃO}

O Aleitamento Materno Exclusivo - AME constitui a forma mais importante, eficaz e econômica de nutrição da criança, pois é através dele que ela irá adquirir proteção contra infecções, além de propiciar o vínculo afetivo entre mãe e filho (MS, 2009).

Segundo dados epidemiológicos, no Brasil, na década de 70 aconteceu um considerável declínio do aleitamento materno: estudos mostraram que a duração da amamentação era de cerca de 30 dias. A partir dessa década, com o Estudo Nacional de Defesa Familiar (ENDEF), pode-se perceber um aumento na prática da amamentação. Outras grandes pesquisas também evidenciaram que $33 \%$ das crianças eram amamentadas aos seis meses de idade na década de 70 e $49 \%$, na década de 80; nos anos 90, essa proporção de crianças amamentadas aumentou 
para mais de $60 \%$, mas apesar de todas essas conquistas, esse aumento está longe do que é preconizada pela Organização Mundial da Saúde - OMS (MS, 2006).

Segundo a OMS e o UNICEF, em torno de seis milhões de vidas de crianças estão sendo salvas a cada ano por causa do aumento das taxas de amamentação exclusiva. A proteção do leite materno contra mortes infantis é maior quanto menor é a criança. Assim, a mortalidade por doenças infecciosas é seis vezes maior em crianças menores de dois meses não amamentadas, diminuindo a medida em que a criança cresce; porém, ainda é o dobro no segundo ano de vida (MS, 2009). O desmame precoce vem sendo considerado um dos problemas de saúde pública, com grande impacto na saúde do lactente menor de seis meses, exigindo dos profissionais de saúde, principalmente do enfermeiro em parceria com a Estratégia de Saúde da Família-ESF, uma assistência mais qualificada nos diversos níveis de atendimento, na promoção de práticas educativas de saúde com mais frequência direcionadas a amamentação com o propósito de melhoria na saúde e prevenção do desmame precoce (AZEREDO et al., 2008).

O amparo dos serviços e profissionais de saúde é fundamental e muito importante para o incentivo do aleitamento materno exclusivo, cabendo ao enfermeiro no atendimento de pré-natal já iniciar esse acompanhamento da gestante junto com toda a equipe da ESF, realizando no decorrer das consultas a formação de grupos de gestantes com seus familiares, com rodas de conversas e reuniões, repassando e esclarecendo todas as informações necessárias e inerentes sobre amamentação. Então, ao analisar essa questão, percebe-se a importância de pesquisar mais a fundo sobre os fatores que estão causando o desmame precoce. Diante do exposto, levantase o seguinte questionamento: o que leva as nutrizes a desistirem de ofertar o aleitamento materno exclusivo até os seis meses de idade do seu filho? $E$ o que isso interfere no desenvolvimento saudável dessas crianças? Dessa forma, o presente estudo objetiva identificar as principais causas do desmame precoce em menores de um ano em uma Estratégia Saúde da Família, bem como conhecer as dificuldades enfrentadas pelas nutrizes na oferta do aleitamento materno exclusivo, analisar a percepção das nutrizes acerca da importância do aleitamento materno exclusivo e identificar o papel do pré-natal no estímulo ao aleitamento materno exclusivo.

\section{MATERIAIS E MÉTODOS}

Trata-se de um estudo e abordagem qualitativa de caráter descritivo, realizada no período de março a abril de 2016 em uma ESF (Estratégia Saúde da Família), localizada na cidade de Juazeiro do Norte. As nutrizes que participaram da pesquisa foram selecionadas de acordo com o seguinte critério de inclusão: nutrizes com seus lactentes menores de um ano que não estão ofertando o aleitamento materno de forma exclusiva. A população é composta por 23 nutrizes com seus lactantes menores de um ano atendidas pela ESF; destas, apenas 6 realizaram o aleitamento materno exclusivo até os seis meses de idade. Outras 17 nutrizes deram início ao desmame precoce, sendo esta a população estudada. 
A coleta de dados aconteceu no mês de março a abril de 2016, após autorização concedida pela Secretaria de Saúde do Município de Juazeiro do Norte (SESAU) e pela equipe da Estratégia de Saúde da Família (ESF) onde o estudo se desenvolveu. As entrevistas aconteceram individualmente na residência de cada nutriz e os dados foram coletados através de um roteiro de entrevista estruturada com auxílio de um gravador, onde foram registradas as informações colhidas junto às participantes.

A análise e interpretação dos dados se basearam na técnica de Bardin (2010), que possibilitou a categorização das falas conforme os seus núcleos temáticos, sendo elas: perfil sócio-demográfico da população, conhecimento prévio sobre aleitamento materno exclusivo e os fatores determinantes no processo de desmame precoce.

A pesquisa segue princípios da resolução 466/12 do Conselho Nacional de Saúde que rege sobre as pesquisas que envolvem os seres humanos. A cada participante foi solicitada anuência para participação na pesquisa, confirmada através da assinatura do TCLE, resguardando, assim, os seus direitos. Para garantir o sigilo das participantes e das informações, foram utilizados nomes fictícios, especificados por nomes de flores.

\section{RESULTADOS E DISCUSSÃO}

O perfil sóciodemográfico desses sujeitos participantes desta pesquisa encontra-se na Tabela 1.

\section{Características do perfil sócio demográfico da população estudada}

Para traçar o perfil da população estudada, focou-se na idade, renda mensal familiar, níveis de escolaridade, quantidade de filhos, e se trabalha fora. 
Tabela 1 - Distribuição das nutrizes por faixa etária, renda mensal, nível de escolaridade, quantidade de filhos e se trabalha fora.

\begin{tabular}{l|c}
\hline FAIXA ETÁRIA & $\mathbf{N}^{\circ}$ \\
\hline 16 a 19 anos & 03 \\
20 a 29 anos & 08 \\
30 a 39 anos & 06 \\
\hline RENDA MENSAL & $\mathbf{N}^{\circ}$ \\
< 1 salário mínimo & 04 \\
De 01 a 02 salários mínimos & 11 \\
De 02 a 03 salários mínimos & 02 \\
\hline NÍVEL DE ESCOLARIDADE & $\mathbf{N}^{\circ}$ \\
\hline Ensino fundamental completo & 01 \\
Ensino fundamental incompleto & 05 \\
$2^{\circ}$ grau completo & 06 \\
$2^{\circ}$ grau incompleto & 03 \\
Ensino superior completo & 01 \\
Ensino superior incompleto & 01 \\
\hline NÚMERO DE FILHOS & $\mathbf{N}^{\circ}$ \\
\hline 01 filho & 10 \\
02 ou mais filhos & 07 \\
\hline MÃES QUE TRABALHAM FORA & $\mathbf{N}^{\circ}$ \\
\hline Sim & 02 \\
Não & 15 \\
\hline QUANTIDADE DE CONSULTAS REALIZADAS NO PRÉ-NATAL & $\mathbf{N}^{\circ}$ \\
\hline 02 a 08 consultas & 03 \\
09 a mais consultas & 14 \\
\hline
\end{tabular}

Fonte: Pesquisa direta em uma Estratégia Saúde da Família no Município de Juazeiro do Norte-CE.

A idade das mães variou entre 16 a 39 anos, com maior predominância entre 20 a 29 anos de idade. A maior parte delas completou o $2^{\circ}$ grau e tem renda mensal familiar de 1 a 2 salários mínimos. Souza et al. (2012), ao estudar Hábitos de Alimentação e Sucção de Bebês Assistidos em Hospital Amigo da Criança, também constatou em seus resultados que as mães com faixa etária de maior prevalência tinham entre 20 a 29 anos, e com renda mensal familiar de um a dois salários mínimos.

Evidencia-se também que a maior parte das nutrizes estudadas eram mães pela primeira vez, ou seja, não tinham experiência previa em amamentar, e que também não trabalhavam fora (apenas duas tinham vinculo empregatício).

Segundo Frota et al. (2009), as experiências das mães, a intenção de amamentar e cada nascimento ocorrem em contextos socioeconômicos diferentes. Assim, o contato prévio com o aleitamento materno talvez não possa ser considerado estímulo suficiente para amamentação dos outros filhos, e sim se essas mães tiveram uma vivência positiva de forma a estabelecê-la novamente com sucesso. Já segundo Fujimori et al. (2010), a amamentação depende da associação de uma série de fatores como condições de vida e de trabalho, do momento vivido pela mulher, de suas experiências anteriores, da sua cultura, e da sociedade.

Nossos resultados mostram que a maioria das mães (14/ 17 nutrizes) referiu ter realizado de 09 a mais consultas do pré-natal, apenas uma disse ter realizado 02 consultas, uma compareceu a 07 consultas, e a outra 08 consultas. 0 objetivo principal do pré-natal e puerpério é acolher a mulher desde o início da gravidez até o 
final de sua gestação, assegurando o nascimento de uma criança saudável, e a garantia do bem-estar materno e neonatal, com qualidade e de forma humanizada com condutas acolhedoras, serviço de saúde com fácil acesso, englobando ações que integrem todos os níveis de atenção (BRASIL, 2005).

Neste trabalho, foi realizada uma entrevista estruturada com as nutrizes atendidas em uma Estratégia Saúde da Família que não estão ou não amamentaram exclusivamente, na busca de investigar quais as principais causas apontadas por elas para dar início ao processo de desmame precoce em seus lactantes menores de um ano. Os dados foram agrupados em 02 (duas) categorias e subcategorias com a finalidade de facilitar a compreensão do leitor, de acordo com as respostas analisadas nas entrevistas. Os textos a seguir foram transcritos conforme a fala das entrevistadas.

\section{Conhecimento prévio sobre aleitamento materno exclusivo:}

$\mathrm{Na}$ amamentação exclusiva não há a necessidade da nutriz fornecer outro alimento, apenas o leite materno; segundo Brasil, Ministério da Saúde (2009): Aleitamento materno exclusivo - quando a criança recebe somente leite materno, direto da mama ou ordenhado, ou leite humano de outra fonte, sem outros líquidos ou sólidos, com exceção de gotas ou xaropes contendo vitaminas, sais de reidratação oral, suplementos minerais ou medicamentos. Nessa categoria foram perguntadas as nutrizes qual seu entendimento a respeito do aleitamento materno exclusivo, tendo como resultados diferentes respostas, destacando que boa parte mostrou saber que o período para o aleitamento materno exclusivo vai até os seis meses de vida da criança.

As falas a seguir demostram os conhecimentos por parte das entrevistadas sobre aleitamento materno exclusivo.

"Sei que é importante pra criança crescer saudável e não há necessidade de outro alimento" (Rosa, 39 anos, dois filhos, lactante de seis meses).

"O que eu entendo que é saudável tanto pra criança como pra mãe [...] e é tão bom a gente amamentar e tem todos os tipos de vitaminas que a criança necessita" (Violeta 38 anos, um filho, lactante de cinco meses).

"Que tem que amamentar até os seis meses só com o leite do peito [...] por que é fundamental pra criança, tem todos os nutrientes" (Jasmim 19 anos, um filho, lactante de cinco meses).

O leite materno é considerado o alimento ideal e contém propriedades nutricionais e imunológicas que garante ao recém-nascido (RN) proteção contra determinadas infecções, permitindo dessa forma que o lactante cresça e se desenvolva de maneira saudável (MARQUES et al., 2011). O aleitamento materno exclusivo deve ser realizado até os seis meses de vida do lactante, conferindo inúmeras vantagens tanto para ele como para a mãe, é rico em nutrientes como vitaminas que são essenciais para o organismo da criança, sem falar no vínculo 
afetivo entre mãe e filho, e várias outras vantagens importantes para ambas as partes (BRASIL. Ministério da Saúde, 2014).

Conforme as falas acima descritas, percebe-se que algumas das nutrizes demostraram ter algum conhecimento de como a amamentação é importante; entretanto, mesmo com esse conhecimento as nutrizes aqui citadas não completaram o processo de amamentação exclusivo até os seis meses. Ressalta-se ainda que duas nutrizes responderam não saber, ou não lembrar sobre o que é aleitamento materno exclusivo.

\section{Fatores determinantes no processo de desmame precoce}

Ao se perguntar às nutrizes sobre as dificuldades e ou motivos que influenciaram na prática do desmame precoce, obteve-se como razão mais mencionada "pouco leite", ou seja, insuficiência na sua produção; o segundo motivo foram os traumas mamilares, e em terceiro o retorno ao trabalho, sendo classificadas aqui como subcategorias da categoria acima citada.

\section{Pouca produção de leite}

As falas a seguir de algumas nutrizes demostram a dificuldade e preocupação que tiveram na produção de leite.

"Num tinha muito leite, não sei se é por que meu seio é pequeno, ai ela mamava e eu via a barriguinha dela seca, por isso comecei a dar outro leite" (Margarida, 23 anos, dois filhos, lactante de oito meses).

"Fui estimulada a produzir leite com massagem, medicação, mas não suficiente pra alimentar ela né, o que saia era um pouquinho de nada, não era suficiente, ai cheguei em casa e mandei meu esposo comprar o NAM, pois não ia deixar a menina com fome a noite toda" (Camélia, 39 anos, uma filha, lactante de nove meses).

"No início quase não tive leite, depois comecei a produzir mais foi muito pouco, então comecei a dar o NESTOGENO com dois meses de idade" (Girassol, 19 anos, um filho, lactante de cinco meses).

Rocci; Fernandes (2013) referem que em algumas circunstâncias a mãe não quer amamentar e usa como justificativa para interromper o aleitamento materno o argumento de que seu leite é fraco ou pouco, não sendo suficiente para nutrir a criança, pois precisam dar satisfação pra si e para os outros do porquê de não terem amamentado.

A concepção de leite fraco ou leite insuficiente é ocasionado por processos biológicos das fases de inibição e estimulação do leite, e isso ocorre devido a práticas inadequadas de amamentação, fazendo com que sejam introduzidos precocemente 
outros alimentos a criança, o que acarreta menor produção do leite materno (MONTESCHIO et al., 2015).

Sabe-se que a produção de leite se dá pelo processo de sucção do bebê, pois quanto mais ele suga, mais leite materno será produzido, e isso depende de práticas de amamentação adequadas, como a pega correta de toda a parte da aureola, e também do interesse da mãe de amamentar. Por isso é importante que as nutrizes sejam orientadas por profissionais capacitados durante todo 0 acompanhamento do pré-natal e puericultura, ensinando as formas corretas de amamentar, esclarecendo dúvidas, medos e receios, de modo que elas possam compreender a importância do aleitamento materno para seus filhos e tenham interesse de amamentá-los até o período recomendado.

\section{Traumas mamilares}

É importante que as nutrizes sejam orientadas quanto à prática adequada da amamentação, pois uma má pega do mamilo ou da auréola leva ao lactente a ter uma sucção deficiente de leite, ocasionando diminuição na produção, e também traumas mamários como fissuras, ingurgitamento das mamas, mastites dentre outros.

Ao serem indagadas se receberam informações sobre amamentação e os direitos que regem e protegem a legislação do aleitamento materno durante as consultas do pré-natal, a maior parte das nutrizes incluída nessa pesquisa respondeu que sim, e que também tiveram até palestras sobre o assunto ministrado na própria unidade.

A seguir relatos de mães que referiram ter tido algum trauma relacionado à mama, fazendo uso de expressões como "machucou, empedrou, rachou, feriu e doeu" para descrever o que dificultou o estabelecimento da amamentação, causando-Ihes vontade de desistir dessa prática:

"Amamentei só ate os dois meses, o leite era só a água, fino, e também meu peito ficou muito ferido" (Orquídea, 26 anos, dois filhos, lactante de dez meses).

"Com um mês já comecei a dar outro leite, meu peito feriu, sangrava muito, tinha que retirar o leite da mama pra dar a ele, doía demais não aguentava dar de mamar" (Tulipa, 20 anos, um filho, lactante de um mês e cinco dias).

"Com três meses já comecei a dar outro leite, ela chorava muito, meu seio também pedrou e feriu” (Acácia, 16 anos, um filho, lactante de onze meses).

Jungles et al. (2010) referem que as rachaduras ou fissuras de modo geral são ocasionadas pela pressão da boca do bebê sobre o mamilo ou sobre a auréola, quando a pega é realizada de forma incorreta, dificultando a amamentação e desencadeando a opção em não amamentar ou desmamar precocemente; às vezes esses fatores podem não ser citados durante o pré-natal, que dá destaque na maioria das vezes apenas à importância do aleitamento. Os problemas mamários podem vir a comprometer qualidade no processo do AM, e a dor, desconforto, estresse e a 
insegurança materna levam as nutrizes a introduzir o uso da mamadeira no intuito de aliviar os sintomas e de suprir as carências nutricionais da criança (MONTESCHIO et al., 2015).

Diante de problemas como estes, faz-se necessário que os profissionais, em especial o enfermeiro, que estão a frente no acompanhamento dessas mulheres e crianças estejam sempre identificando tais problemas e traçando intervenções eficazes na busca de solucioná-los para que não venham intervir na promoção de uma prática de amamentação com qualidade.

\section{Retorno ao trabalho}

Foram poucas as nutrizes a relatar o trabalho como sendo um fator para o desmame precoce, pois a maior parte delas não estava trabalhando no momento. $\mathrm{A}$ seguir, relatos de duas delas sobre ter iniciado o desmame devido ter que retornar ao trabalho.

"Amamentei até os seis meses só com o leite do peito, ai comecei a dar outro leite o NINHO [...] comecei a dar logo pra ele ir se acostumando, pois tinha que voltar a trabalhar [...] com cinco meses ele já não queria mais mamar, pois se acostumou com o outro leite" (Copo de leite, 19 anos, um filho lactante de oito meses).

"Com quatro meses comecei a dar agua a ela, pois trabalho fora, ai deixo ela com minha mãe, então tirava o leite colocava pra conservar, mais mesmo assim ela dava agua, e eu também dou quando estou em casa, por conta do tempo muito quente" (Flor do dia, 39 anos, dois filhos, lactante de seis meses).

Salustiano et al. (2012) constatam que dentre os fatores que influenciam a prática do desmame precoce, destaca-se o trabalho materno, considerado como fator de proteção da prática do AME a presença da mãe em casa; porém, ressalta que nem sempre a presença dela em casa significa a ausência de trabalho, pois visto que a mesma exerce afazeres domésticos e também pode ter atividades profissionais no domicílio, sendo estes dois últimos também não analisados na sua pesquisa.

Conde e Okasaki (2005) relatam na sua pesquisa que o trabalho materno não pode ser considerado como um dos fatores para o desmame precoce, visto que a nutriz tem direito a um período de 120 dias de licença maternidade, que corresponde a quatro meses de vida do lactante; nesse período ela poderá amamentar exclusivamente e logo após realizar a ordenha e armazenamento do seu leite para ser oferecido ao seu bebê, com o uso de copinho. A nutriz também deverá ser orientada quanto aos seus direitos como mãelnutriz e cidadã, conforme as leis que protegem o aleitamento materno, tendo direito a usufruir, por exemplo, o auxilio creche, disponibilidade de horário, licença maternidade dentre outros.

Ressalta-se ainda ter encontrado duas mães que relataram não terem tido problema algum durante o processo de aleitamento materno exclusivo, mais que introduziram outro alimento antes dos seis meses tais como água, chás, por acharem necessários para a criança segundo elas. 
O apoio da família também é um fator muito importante na realização da pratica da amamentação, na sua continuidade, e diante das dificuldades e adversidades vividas por elas no seu dia a dia. Diante disso, destaca-se que mesmo com os problemas relatados pelas nutrizes em amamentar, as mesmas ao serem perguntadas responderam que tiveram apoio familiar de mãe, esposo, sogra e irmã, etc.

\section{CONSIDERAÇÕES FINAIS}

O aleitamento materno exclusivo é o alimento ideal para ser fornecidos ao RN desde o nascimento até os seis meses de vida do lactante, pois é completo, já vem pronto, na temperatura ideal, é de baixo custo, devendo ser complementado com outros alimentos a partir desses seis meses até dois anos ou mais. Segundo os resultados apresentados, foi possível verificar que entre a população de nutrizes com seus lactantes menores de um ano assistidos pela ESF, a maioria deu início ao processo de desmame precoce. O desmame precoce vem sendo considerado como um dos problemas de saúde pública que interfere no processo de desenvolvimento e crescimento saudável da criança, trazendo uma série de fatores prejudiciais à saúde do lactante, que irá repercutir ao longo do seu desenvolvimento, e é também uma das causas do aumento nas taxas de mortalidade infantil.

Conclui-se que os fatores predominantes de desmame precoce são a ideia de pouca produção de leite materno, os traumas mamilares e o retorno ao trabalho.

O pré-natal é fundamental no acompanhamento dessas mulheres, pois é através dele que os profissionais, principalmente o enfermeiro, irão fornecer as informações importantes e inerentes sobre o AM, incluindo todos os problemas que poderão ocorrer durante a gestação e período da amamentação, esclarecendo dúvidas e minimizando os medos e receios. Também deverá ser dada a continuidade a esses cuidados durante visitas domiciliares e no acompanhamento da criança durante as consultas de puericultura, nas quais será verificado o desenvolvimento do lactante. Então diante do exposto, abrem-se lacunas em relação a outros fatores que possam interferir e influenciar essas nutrizes a desmamar esses lactantes antes do período recomendado, deixando espaço para novas pesquisas, avanços e estudos enfocando a temática abordada. É importante que os profissionais da saúde em geral estejam mais motivados e agregados na construção de meios estratégicos que possam despertar nessas mulheres o interesse de realizar a pratica da amamentação, trabalhando em parceria com outras ESF e também com poder público na busca de reverter o quadro do desmame.

Conflito de interesse: Os autores declaram inexistência de conflito de interesse na realização deste trabalho. 


\section{REFERÊNCIAS}

AZEREDO, C. M. et al. Percepção de mães e profissionais de saúde sobre o aleitamento materno: encontros e desencontros. Rev. Paul. Pediatr, v.26, p. 336344, 2008.

BARDIN, L. Análise de Conteúdo. Lisboa, Portugal: Edições 70, LDA, 2010.

BRASIL. Ministério da Saúde. Secretaria de Atenção à Saúde. Departamento de Atenção Básica. Saúde da criança: nutrição infantil: aleitamento materno e alimentação complementar. Brasília: Editora do Ministério da Saúde, 2009. (Série A. Normas e Manuais Técnicos) (Cadernos de Atenção Básica, n. 23).

. Departamento de Atenção Básica. Indicadores de

vigilância alimentar e nutricional. Brasil 2006. Brasília: Ministério da Saúde, 2006.

. Departamento de Ações Programáticas Estratégicas. Área

Técnica de Saúde da Mulher. Pré-natal e Puerpério: atenção qualificada e humanizada- manual técnicolMinistério da Saúde- Brasília, 2005.

. Departamento de Atenção Básica. Saúde da criança:

crescimento e desenvolvimento. 1. ed., 2. reimp. Brasília: Ministério da Saúde, 2014.

CONDE, V. S.; OKASAKI, E. L. F. J. Fatores de risco para desmame precoce:

proposta para intervenções de enfermagem. Rev de Enferm UNISA, v.6, p. 104108, 2005.

FROTA, M. A. et al. Fatores que interferem no aleitamento materno. Rev Rene, v.10, p.61-67, 2012.

FUJIMORI, E. et al. Aspectos relacionados ao estabelecimento e à manutenção do aleitamento materno exclusivo na perspectiva de mulheres atendidas em uma unidade básica de saúde. Interface, v.14, p. 315-327, 2010.

JUNGES, C. F. et al. Percepções de puérperas quanto aos fatores que influenciam o aleitamento materno. Rev. Gaúcha Enferm, v.31, p. 343-350, 2010.

MARQUES, E. S.; COTTA, R. M. M.; PRIORE SE. Mitos e crenças sobre o aleitamento materno. Ciência \& Saúde Coletiva, v.16, p. 2461-2468, 2010.

MONTESCHIO, C. A. C.; GAIVA, M. A. M.; MOREIRA, M. D. S. O enfermeiro frente ao desmame precoce na consulta de enfermagem à criança. Rev. Bras. Enferm, v. 68, p. 869-875, 2015.

ROCCI, E.; FERNANDES, R. A. Q. Dificuldades no aleitamento materno e influência no desmame precoce. Rev. Bras. Enferm, v. 67, p. 22-27, 2010. 
SALUSTIANO, L. P. Q. et al. Fatores associados à duração do aleitamento materno em crianças menores de seis meses. Rev. Bras. Ginecol. Obstet. v. 34, p. 28-33, 2012.

SOUSA, R. V. et al. Hábitos de alimentação e sucção de bebês assistidos em Hospital Amigo Da Criança. Pesq. Bras. Odontopediatria Clín. Integr, v. 12, p. 245250, 2012.

Artigo recebido em: 19/04/2017

Artigo aprovado em: 21/11/2017

Artigo publicado em: 20/12/2017 